\title{
Productivity and Reallocation: Evidence from the Universe of Italian Firms
}

\author{
Andrea Linarello and Andrea Petrella \\ Bank of Italy, Structural Economic Analysis Directorate ${ }^{1}$
}

ABSTRACT

This article investigates the contribution of allocative efficiency to aggregate labour productivity growth in Italy between 2005 and 2013. Exploiting a unique dataset that covers the universe of firms, we find that allocative efficiency increased during the period of observation. We show that the dynamics of aggregate labour productivity benefited from the reallocation of resources among continuing firms and from the net effect of business demography. Among industries, we find that reallocation has been stronger in industries that are more exposed to import competition from developing countries. Moreover, we document that the observed adjustments have not evenly affected all firms across the productivity distribution: selection has become tougher for firms belonging to the lower tail, forcing the exit of the least productive firms and favoring the reallocation of the workforce to the best performing ones.

Thanks to the increasing availability of firmlevel data, a growing theoretical and empirical literature has documented large and persistent productivity differences across countries and firms within narrowly defined sectors (Bartelsman et al., 2005). This research agenda has considerably improved our understanding of aggregate productivity dynamics by highlighting two distinct mechanisms of adjustment. On the one hand, aggregate productivity is the result of technological and managerial decisions made by entrepreneurs (Aghion et al., 2009; Bloom and Van Reenen, 2010); on the other hand, it reflects the ability of an economy to allocate resources towards its most productive units (Hsieh and Klenow, 2009).

Several studies have documented that the share of aggregate productivity explained by the latter, i.e. allocative efficiency, is substantial in an accounting sense. In the United States it accounts for 50 per cent of aggregate labour productivity; ${ }^{2}$ in Europe its importance is smaller and ranges between 15 and 38 per cent (Bartelsman et al., 2009). Moreover, it explains a substantial part of productivity differentials among countries (Andrews and Cingano, 2014). Intuitively, the larger the share of employment that goes to more productive firms, the higher the aggregate productivity.

1 The authors are advisors in the Structural Economic Analysis Directorate at the Bank of Italy. They are grateful to Matteo Bugamelli, Francesca Lotti, Paolo Sestito and Corrado Abbate for helpful comments, as well as Maria Gabriela Ladu for excellent research assistance. This article also benefited from the comments of two anonymous referees and the editor. The views expressed herein are those of the authors and do not involve the responsibility of the Bank of Italy. Emails: andrea.linarello@bancaditalia.it; andrea.petrella@bancaditalia.it.

2 Allocative efficiency is defined as zero when resources are randomly allocated across firms. In this situation aggregate labour productivity would be 50 per cent lower than the actual level. 
One interesting conclusion of this line of research is that misallocation of resources across firms due to frictions in factor and output markets may lower aggregate productivity.

Despite the increasing interest from both academic researchers and policy makers on misallocation, the most instructive measure of firm-level heterogeneity to detect possible distortions in the allocation of resources still is debated. Following the pioneering contribution of Hsieh and Klenow (2009), several studies used the dispersion in revenue productivity to proxy for misallocation. Although Hsieh and Klenow (2009) acknowledge that dispersion of marginal revenue products alone cannot be interpreted as misallocation because the results might be influenced by measurement error and model misspecification, the importance of these two factors in explaining productivity gaps is still an open question. Recently, however, Bartelsman et al. (2013) argued, both theoretically and empirically, that within-industry covariance between size and productivity, also known as OP covariance (Olley and Pakes, 1996), is a robust measure to assess misallocation.

In this article we will focus on labour productivity dynamics in Italy, which has been disappointing with respect to its main Euro area partners; in particular, our aim is to investigate the contribution of allocative efficiency to its aggregate dynamic. We take advantage of a unique dataset covering the universe of Italian firms operating in the private business nonagriculture and non-financial sector over the period 2005-2013. Data on the universe of firms, while largely available for other countries (among others, United States, France and Belgium), is new for Italy and it is the outcome of a collaboration between the Bank of Italy (BoI) and the Italian National Statistical Agency (ISTAT). The dataset combines information from several statistical, administrative and fiscal sources. It contains information on firm location, legal form, date of incorporation, industry classification, number of persons employed, turnover and value added.

In order to assess the importance of allocative efficiency in Italy, we follow Olley and Pakes (OP) (1996) and decompose aggregate labour productivity into the unweighted firm-level average productivity and the OP covariance term between labour productivity and size. We find that the contribution of the OP covariance to aggregate labour productivity increased by almost 7 percentage points between 2005 and 2013. We then apply the dynamic decomposition proposed by Melitz and Polanec (2015) to aggregate labour productivity growth. This allows us to distinguish between two mechanisms affecting allocative efficiency: first, the reallocation of resources among existing firms; second, the selection, i.e. entry and exit, of firms in the market.

Our results show that, among incumbents, between 2005 and 2013 the reallocation component contributed positively to aggregate productivity growth. Its contribution was larger (in absolute value), with the exception of some years during the crisis, than the decline observed throughout the entire period in average productivity. The net contribution of firm demography is always positive in our data: the exit of the least productive firms more than compensates the entry of newborn firms, whose productivity level is on average lower than that of incumbent firms.

We then look at the correlation between our measures of reallocation and selection and some industry structural characteristics. Not surprisingly, when we focus on the effect of the business cycle, we find that average productivity and reallocation among existing firms increased more in the industries experiencing a boom. This is consistent with the evidence that firms invest in productivity-enhancing technology 
and machinery when they experience an increase in market size (Syverson, 2011). We also document that the contribution of entry and exit to aggregate productivity growth is countercyclical, i.e. it is lower in industries that experience a boom. This result is consistent with the cleansing hypothesis, i.e. that recessions are periods of tougher selection for business initiatives (Caballero and Hammour, 1994; Foster et al., 2014). Moreover, we show that the reallocation effect is stronger in sectors that were more exposed to competition from developing countries; a fiercer competitive environment - especially in low value-added sectors - might have favored an improvement of allocative efficiency through the exit of the least productive firms and the reallocation of resources towards the most productive ones. A similar mechanism has been highlighted for United States manufacturing firms by Bernard $e t$ al. (2006), as a consequence of the exposure to low-wage country imports.

We conclude our analysis by providing some suggestive evidence of the underlying forces behind the observed increase in allocative efficiency. We explore the role of firm entry, exit and employment growth along the productivity distribution. Between 2005 and 2013, we find that the entry rate declined and the exit rate increased for firms in the low tail of the productivity distribution. Moreover, average employment growth declined for all percentiles of the productivity distribution: in particular employment growth became negative for the least productive firms, while it remained positive for the most productive ones. These results suggest that the Italian economy undertook some structural adjustments, eventually reinforced during the crisis, that led to the exit of low productivity firms and that favored the reallocation of workforce towards the best performing ones.

Taken as a whole, our results suggest that behind the poor productivity performance of the Italian economy, which is driven by the decline in average productivity within firms, the reallocation of inputs and business demography show positive dynamics. There are, however, some drawbacks in the measure of productivity and allocative efficiency that we use that deserve some discussion. First, our measure of productivity (value added per worker) might not be informative about the underling dynamics of technical efficiency, as it may reflect changes in prices and markups. Second, the correlation between changes in the $\mathrm{OP}$ covariance and dispersion-based measures of misallocation (in the spirit of Hsieh and Klenow (2009)) can be either positive or negative from a theoretical point of view, suggesting that some caution is needed when interpreting the evidence arising from either of these two measures. Finally, although the OP covariance has attractive features, it can be negatively correlated with model-based measures, where the dynamics of aggregate productivity are typically captured by changes in output that are not explained by changes in inputs expenditure (in the spirit of Solow (1957). ${ }^{3}$

Recently, several studies have explored the misallocation hypothesis as one of the possible causes behind the productivity slowdown experienced by many advanced economies (Cette $e t$ al., 2016). Gopinath et al. (2015) show that the decline in real interest rates, observed in Southern Europe, was associated with capital inflows increasingly misallocated towards firms with high net worth, though not necessarily being the most productive. García-Santana et al. (2016) document, for the case of Spain, that the increase in misallocation has been more severe
3 See Petrin and Levinsohn (2012) for a detailed discussion. 
in those industries in which the influence of the public sector is larger (e.g. through licensing or regulations).

Several contributions have also analyzed the role of allocative efficiency in Italy. Gamberoni et al. (2016) - using data on incorporated firms with more than 20 employees show an increase in allocative efficiency after the global financial crisis in Italy, as well as in other European countries. Calligaris et al. (2016), using data on incorporated firms, document for the Italian manufacturing sector an increase in allocative efficiency starting in 2008.

The evidence provided in this article is broadly in line with the analysis conducted so far on the Italian case, highlighting a significant role of allocative efficiency in shaping productivity dynamics. However, while existing studies struggle to find a positive reallocation of labour before 2008, our results show that the contribution of the OP covariance to aggregate productivity growth before the crisis was positive, although limited. Part of this discrepancy can be attributed, as discussed above, to the different methodology used to measure misallocation. Another important difference is due to data sources used: as a matter of fact, while the existing evidence on allocative efficiency in Italy is limited to the subsample of incorporated firms, one of our main contributions to the current debate is that of using data for a much broader set of firms. Moreover, we propose a simple, though effective, method to exploit the detailed sectoral disaggregation of our dataset, in order to net out our results from sectoral composition effects and cyclical conditions at the sector level.

\section{Data}

Our firm-level dataset covers all active firms for 2005 to 2013, i.e. firms whose production processes were active for at least 6 months in a given business year. The construction of the dataset is the result of collaboration between the Bank of Italy (BoI) and the Italian National Statistical Agency (ISTAT). The dataset combines information from the business registry (Archivio Statistico delle Imprese Attive - ASIA) with other statistical, administrative and fiscal sources. It contains information on firm location, legal status, incorporation date, industry classification (NACE rev. 2), number of persons employed, turnover, and value added. ${ }^{4}$

The construction heavily relies on work done at ISTAT over the past few years for the construction of the FRAME-SBS dataset, an integrated firm-level census dataset that covers all active firms. While the census FRAME-SBS represents the source of information in our dataset starting from 2012, the joint effort of BoI and ISTAT contributed to filling the gaps backwards and building a longer time series of data, suitable for studying the evolution of the Italian economy starting from the mid- 2000s.

Our aim is to exploit the microeconomic heterogeneity behind aggregate trends in labour productivity. With this aim at hand, we exclude from our dataset several sectors. First, we exclude agriculture, mining and quarries (NACE divisions 1-9), and regulated sectors such as gas, energy and waste (NACE divisions 35-39) for which labour productivity dynamics could reflect changes in prices that are independent from the firms' underlying productivity. Second, we exclude the financial sector (NACE divisions 64-66) for which data are not available. Third, we exclude the non-business service sector (NACE divisions 84-88 and 90-99), because their overlapping with the public sector might influence the productivity dynamics. Finally we exclude some sectors for which aggregate labour productivity computed using firm-level data significantly diverges from estimates inferred from National Account data. ${ }^{5}$

4 See Abbate et al. (2017) for a detailed description of the dataset 
Chart: 1 Comparison between ASIA Database and Italian National Accounts Estimate of Value Added and Value Added Per Worker, 2006 - 2013

A) VA growth rate
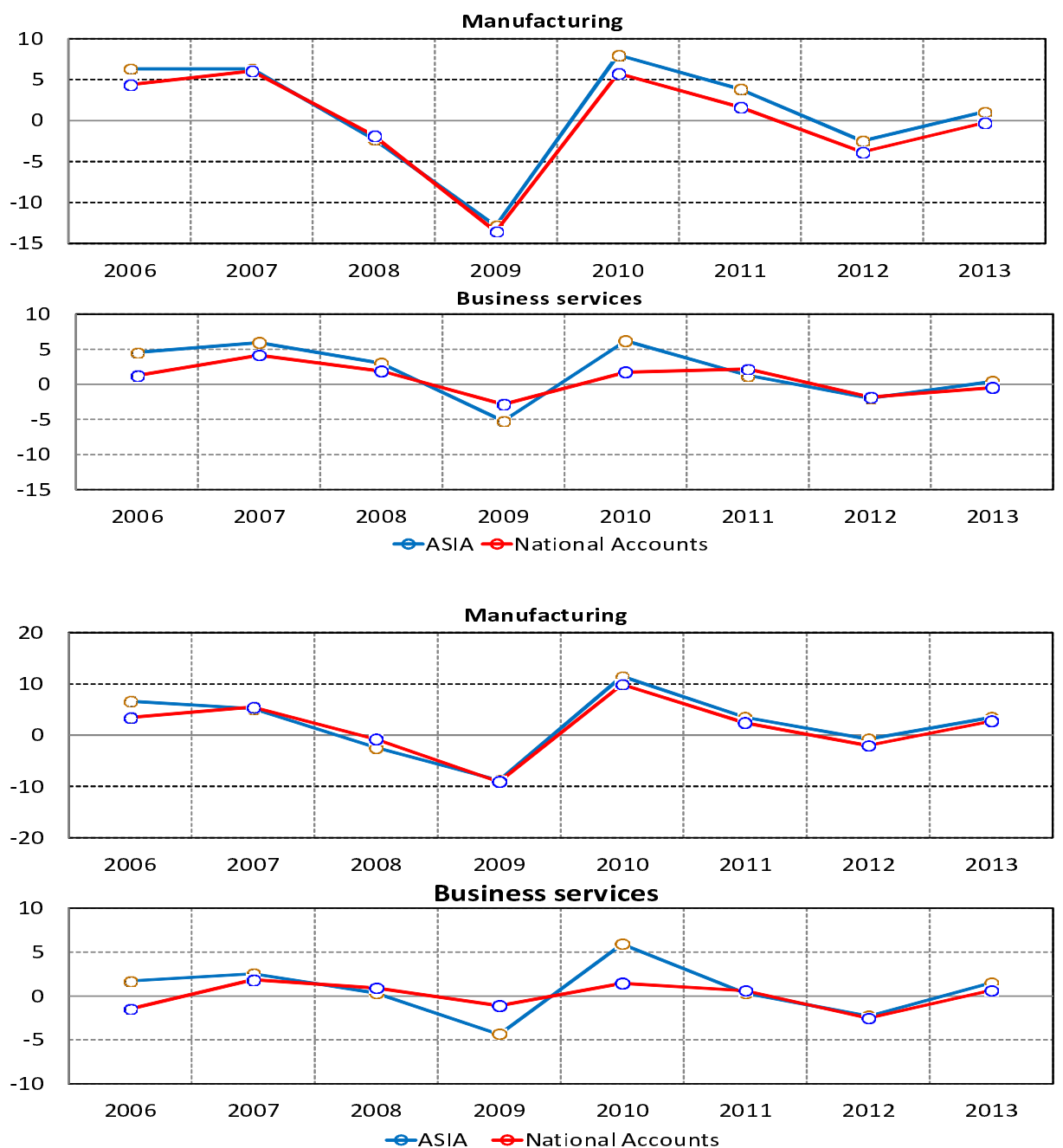

Source: Own elaborations on Istat data

At the aggregate level, our firm-level dataset closely tracks National Accounts data. Panel (a) of Chart 1 compares the growth rates of value added between the two data sources, for manufacturing and business services separately; panel (b) shows the comparison for the growth rates of labour productivity. In the manufacturing sector, the goodness of fit for both value added and labour productivity dynamic is excellent. Some differences emerge in the business services sector, largely due to the fact that National Account data include estimates of the underground economy and illegal workforce, that weigh more in business services than in manufacturing. According to the latest official figures, the illegal economy accounts for 7 per cent

5 We exclude from the analysis NACE divisions 19 (Manufacture of coke and refined petroleum products), 41-43 (construction), 53 (Postal and courier activities), 61 (Telecommunication) and 68 (Real estate activities). See Table B.1 in the appendix for a complete list of sectors used in the analysis. The full appendix can be found in the full online version at: http://www.csls.ca/ipm/32/Linarello_Petrella\%20Appendix.pdf 
Table 1: Descriptive Statistics for the ASIA Dataset, 2005-2013

Levels and Growth Rates

\begin{tabular}{|c|c|c|c|c|c|}
\hline & \# of firms & \# of employees & $\begin{array}{c}\text { Value added } \\
\text { (Millions of Euros) }\end{array}$ & $\begin{array}{r}\text { Value added per } \\
\text { employee (Euros) }\end{array}$ & $\begin{array}{c}\text { Employees per } \\
\text { firm }\end{array}$ \\
\hline \multicolumn{6}{|c|}{ Manufacturing } \\
\hline 2005 & 443,623 & $4,092,856$ & 196.08 & 47.91 & 9.23 \\
\hline 2006 & 437,926 & $4,088,521$ & 209.10 & 51.14 & 9.34 \\
\hline 2007 & 432,761 & $4,132,101$ & 215.39 & 52.13 & 9.55 \\
\hline 2008 & 426,798 & $4,138,323$ & 208.78 & 50.45 & 9.70 \\
\hline 2009 & 412,571 & $3,961,776$ & 173.79 & 43.87 & 9.60 \\
\hline 2010 & 402,670 & $3,842,702$ & 193.35 & 50.32 & 9.54 \\
\hline 2011 & 404,919 & $3,847,575$ & 201.37 & 52.34 & 9.50 \\
\hline 2012 & 414,524 & $3,858,736$ & 197.73 & 51.24 & 9.31 \\
\hline 2013 & 407,047 & $3,769,859$ & 196.60 & 52.15 & 9.26 \\
\hline 2005--06 & -1.28 & -0.11 & 6.64 & 6.75 & 1.19 \\
\hline 2006--07 & -1.18 & 1.07 & 3.01 & 1.92 & 2.27 \\
\hline 2007--08 & -1.38 & 0.15 & -3.07 & -3.22 & 1.55 \\
\hline 2008--09 & -3.33 & -4.27 & -16.76 & -13.05 & -0.96 \\
\hline 2009--10 & -2.40 & -3.01 & 11.25 & 14.70 & -0.62 \\
\hline 2010--11 & 0.56 & 0.13 & 4.15 & 4.02 & -0.43 \\
\hline 2011--12 & 2.37 & 0.29 & -1.81 & -2.09 & -2.03 \\
\hline 2012--13 & -1.80 & -2.30 & -0.57 & 1.77 & -0.51 \\
\hline 2005--13 & -8.24 & -7.89 & 0.27 & 8.86 & 0.38 \\
\hline \multicolumn{6}{|c|}{ Services } \\
\hline 2005 & $2,467,007$ & $7,702,550$ & 287.35 & 37.31 & 3.12 \\
\hline 2006 & $2,486,227$ & $7,943,321$ & 301.96 & 38.02 & 3.19 \\
\hline 2007 & $2,529,322$ & $8,219,761$ & 313.32 & 38.12 & 3.25 \\
\hline 2008 & $2,543,113$ & $8,443,327$ & 311.82 & 36.93 & 3.32 \\
\hline 2009 & $2,515,252$ & $8,357,716$ & 284.29 & 34.02 & 3.32 \\
\hline 2010 & $2,518,288$ & $8,405,556$ & 303.17 & 36.07 & 3.34 \\
\hline 2011 & $2,513,429$ & $8,490,370$ & 302.14 & 35.59 & 3.38 \\
\hline 2012 & $2,543,379$ & $8,626,073$ & 291.13 & 33.75 & 3.39 \\
\hline 2013 & $2,517,042$ & $8,526,864$ & 288.29 & 33.81 & 3.39 \\
\hline 2005--06 & 0.78 & 3.13 & 5.09 & 1.90 & 2.33 \\
\hline 2006--07 & 1.73 & 3.48 & 3.76 & 0.27 & 1.72 \\
\hline 2007--08 & 0.55 & 2.72 & -0.48 & -3.11 & 2.16 \\
\hline 2008--09 & -1.10 & -1.01 & -8.83 & -7.89 & 0.08 \\
\hline 2009--10 & 0.12 & 0.57 & 6.64 & 6.03 & 0.45 \\
\hline 2010--11 & -0.19 & 1.01 & -0.34 & -1.34 & 1.20 \\
\hline 2011--12 & 1.19 & 1.60 & -3.64 & -5.16 & 0.40 \\
\hline 2012--13 & -1.04 & -1.15 & -0.98 & 0.18 & -0.12 \\
\hline 2005--13 & 2.03 & 10.70 & 0.33 & -9.37 & 8.50 \\
\hline \multicolumn{6}{|c|}{ Total } \\
\hline 2005 & $2,910,630$ & $11,795,406$ & 483,424 & 40.98 & 4.05 \\
\hline 2006 & $2,924,153$ & $12,031,842$ & 511,059 & 42.48 & 4.11 \\
\hline 2007 & $2,962,083$ & $12,351,862$ & 528,703 & 42.80 & 4.17 \\
\hline 2008 & $2,969,911$ & $12,581,650$ & 520,590 & 41.38 & 4.24 \\
\hline 2009 & $2,927,823$ & $12,319,492$ & 458,079 & 37.18 & 4.21 \\
\hline 2010 & $2,920,958$ & $12,248,258$ & 496,513 & 40.54 & 4.19 \\
\hline 2011 & $2,918,348$ & $12,337,945$ & 503,505 & 40.81 & 4.23 \\
\hline 2012 & $2,957,903$ & $12,484,809$ & 488,857 & 39.16 & 4.22 \\
\hline 2013 & $2,924,089$ & $12,296,723$ & 484,891 & 39.43 & 4.21 \\
\hline 2005--06 & 0.46 & 2.00 & 5.72 & 3.64 & 1.53 \\
\hline 2006--07 & 1.30 & 2.66 & 3.45 & 0.77 & 1.35 \\
\hline 2007--08 & 0.26 & 1.86 & -1.53 & -3.33 & 1.59 \\
\hline 2008--09 & -1.42 & -2.08 & -12.01 & -10.14 & -0.68 \\
\hline 2009--10 & -0.23 & -0.58 & 8.39 & 9.02 & -0.34 \\
\hline 2010--11 & -0.09 & 0.73 & 1.41 & 0.67 & 0.82 \\
\hline 2011--12 & 1.36 & 1.19 & -2.91 & -4.05 & -0.16 \\
\hline 2012--13 & -1.14 & -1.51 & -0.81 & 0.71 & -0.37 \\
\hline 2005--13 & 0.46 & 4.25 & 0.30 & -3.79 & 3.77 \\
\hline
\end{tabular}

Note Figures for 2005-2013 are cumulative per cent changes.

Source: 0wn elaborations on Istat data. 
of people employed and 6 per cent of value added in manufacturing, against 16 per cent and more than 20 per cent in business services.

Tables 1 and 2 report descriptive statistics from our firm-level dataset. The number of firms in the manufacturing sector declined almost every year; in 2013 there were about 36,000 fewer firms than in 2005. In business services, the number of firms does not exhibit a clear pattern, and in 2013 there were more firms than at the beginning of the period. Between 2005 and 2013, average firm size measured by the number of persons employed - increased in both sectors: in 2013 the average firm employed 9.3 people in the manufacturing sector and 3.4 in the business service sector.

In our final dataset, aggregate labour productivity - measured as real value added per employee - increased between 2005 and 2007, and declined during the global financial crisis (2007-09) and the sovereign debt crisis (201113); overall, it was 3.8 per cent lower in 2013 than in 2005. The aggregate dynamics reflect different patterns between manufacturing and services: in the former, aggregate labour productivity increased 8.9 per cent between 2005 and 2013, while in the latter it declined by 9.4 per cent. Before the crisis, the increase of labour productivity in the manufacturing sector was due to a rise of value added greater than the one of employment after 2008; instead, the adjustment of the labour force has been stronger. In business services, the negative growth of aggregate labour productivity reflects both a constant increase in the number of people employed, and a decline in value added since 2007.

\section{Productivity Decompositions}

Aggregate labour productivity $(\Phi)$ in year $\mathrm{t}$ corresponds to the weighted average of the individual firm's productivity $\left(\rho_{\mathrm{i}}\right)$, with the weights $\left(\omega_{\mathrm{i}}\right)$ being the firms' share of total employees. More formally:

$$
\Phi_{t}=\sum_{i=1}^{\eta} \rho_{i t} \omega_{i t}
$$

Aggregate productivity can be further decomposed as the sum of the unweighted average firm productivity $(\bar{\rho})$ and the covariance between firm productivity and the share of employees:

$$
\begin{aligned}
& \Phi_{t}=\bar{\rho}_{t}+\operatorname{Cov}\left(\rho_{i t}, \omega_{i t}\right) \\
& \eta \\
& =\bar{\rho}_{t}+\sum\left(\rho_{i t}-\bar{\rho}_{t}\right)\left(\omega_{i t}-\bar{\omega}_{t}\right)
\end{aligned}
$$

The covariance term is often referred to as static "Olley and Pakes (OP) covariance". In Olley and Pakes (1996), this decomposition applied to the US telecommunications industry - allowed the authors to distinguish between the efficiency gains deriving from a reallocation of resources towards the most productive firms (measured by the increase in the $\mathrm{OP}$ covariance), and those arising from the productivity growth of individual firms (captured by the changes in the average productivity term). The former component has been found to explain the largest share of the observed productivity gain.

Recent developments in the economic literature devote increasing attention to allocative efficiency, since it reflects institutional and regulatory features that distort the functioning of the markets. As an example, Olley and Pakes (1996) document that, in the 1980s, the aggregate productivity of the US telecommunications industry grew considerably after an episode of market liberalization, and that this increase was largely due to an improvement of allocative efficiency. In another study, Bartelsman et al. (2013) quantify the contribution of 
allocative efficiency, by showing that US aggregate labour productivity is roughly 50 per cent higher with respect to a hypothetical scenario where workers are randomly allocated across firms.

In addition to studying the contribution of allocative efficiency to aggregate productivity, it is possible to analyze the dynamics of aggregate productivity through a decomposition that assesses - for any pair of years the relative contribution of three groups of firms: the ones that survive (also called incumbents), entrants and exiting firms. The demographic processes play a role in determining the productivity dynamics, since entrants and exiting firms are different (also with respect to the incumbents) in terms of productivity. For incumbents, it is possible to further distinguish the contribution of two more components: (i) the variation in the efficiency of individual firms (so-called within margin); and (ii) the reallocation of resources to firms characterized by different productivity levels (so-called between margin).

In order to rewrite equation (2) in dynamic terms, firms are divided in three groups $\mathrm{g}$, as mentioned above: ${ }^{6}$ entrants (E) that were not active at time $\mathrm{t}-1$ and enter the market at time t; exiting (X) firms that were active at time $\mathrm{t}-1$ and exit from the market at time $t$; and incumbents (S) that are active on the market in both periods. With these definitions in hand, equation

(2) can be rewritten as:

$\eta$

$$
\Phi_{t}=\sum_{i=1} \rho_{i t} \omega_{i t}=\sum_{g \varepsilon G} \Phi_{g t}{ }^{\omega} g t
$$

where the weights $\mathrm{w}_{g t}$ correspond to the share of employees in group $\mathrm{g}, \mathrm{F}_{g t}$ represents the aggregate productivity of group $g$, and $\mathrm{G}=\{\mathrm{E}$, $X, S\}$.

A dynamic version of equation (2) can be derived based on the methodology - known as dynamic OP decomposition - recently proposed by Melitz and Polanec (2015). Considering two consecutive time periods, it is possible to express the aggregate productivity of the first period $\left(\Phi_{1}\right)$ as the weighted average of the productivity of the firms that will survive and that of the firms that will exit the market; analogously, the aggregate productivity of the second period $\left(\Phi_{2}\right)$ can be expressed as the weighted average of the productivity of the firms that have survived and that of the firms that have entered the market:

$$
\begin{aligned}
& \Phi_{1}=\Phi_{S 1} \omega_{S 1}+\Phi_{X 1} \omega_{X 1} \\
& \Phi_{2}=\Phi_{S 2}{ }^{\omega_{S 2}}+\Phi_{E 2}{ }^{\omega_{E 2}}
\end{aligned}
$$

The difference between $\ddot{O}_{2}$ and $\ddot{O}_{1}$ returns the variation in aggregate productivity:

$$
\begin{aligned}
& \Phi_{2}-\Phi_{1}=\left(\Phi_{S 2}-\Phi_{S 1}\right) \\
& +\omega_{E 2}\left(\Phi_{E 2}-\Phi_{S 2}\right) \\
& +\omega_{X 1}\left(\Phi_{S 1}-\Phi_{X 1}\right)
\end{aligned}
$$

where the first term $\left(\Phi_{S 2}-\Phi_{S 1}\right)$ represents the productivity variation for the firms that are active on the market in both periods (the incumbents); the second $\left(\Phi_{\mathrm{E} 2}-\Phi_{\mathrm{S} 2}\right)$ is the contribution of entrants, which is positive (negative) if their productivity is higher (lower) than that of the incumbent firms; the third $\left(\Phi_{\mathrm{S} 1}\right.$ $\left.\Phi_{\mathrm{X} 1}\right)$ is the contribution of firms that exit the market, which is positive (negative) if their productivity is lower (higher) than that of the incumbents. The term $\left(\Phi_{\mathrm{S} 2}-\Phi_{\mathrm{S} 1}\right)$ can be further decomposed into the variation of the

6 In all the analyses presented below, firm demography has been purged of false entrants and false exits, in the spirit of Geurts and Van Biesebroeck (2014). To identify false entry and exits, we use an administrative register of events that collects information on corporate operations. As a consequence, we are able to exclude from our data operations such as mergers and spinoffs. 
incumbents' average productivity $\left(\Delta \bar{\rho}_{S}\right)$ and the one of the covariance between incumbents' productivity and the share of employees $\left(\Delta \operatorname{Cov}_{S}\right)$, capturing the intensity of the reallocation process. To sum up, the variation of aggregate productivity can be expressed as the sum of the following four components (the first being average productivity, followed by reallocation, entry and exit respectively):

$$
\begin{aligned}
& \Phi_{2}-\Phi_{1}=\Delta \bar{\rho}_{s}+\Delta \operatorname{Cov}_{S} \\
& +\omega_{E 2}\left(\Phi_{E 2}-\Phi_{S 2}\right) \\
& +\omega_{X 1}\left(\Phi_{S 1}-\Phi_{X 1}\right)
\end{aligned}
$$

where the sum of average productivity and reallocation add up to the contribution of the incumbents, and the sum of entry and exit add up to the contribution of net firm demography. ${ }^{7}$

\section{Results \\ Baseline Results}

We first have applied the static decomposition in equation (2) to Italian aggregate labour productivity for the total economy, and for manufacturing and services separately. In the 2005-13 period, the weight of allocative efficiency $\left(\left(\operatorname{Cov}\left(\rho_{i t}, \omega_{i t}\right)\right) / \Phi_{t}\right)$ has risen by nearly 7 percentage points from 35.3 per cent to 42.2 per cent at the end of the period, growing more strongly and steadily in manufacturing than in services. In Appendix Table B1 we report the static OP contribution for each 2-digit sector between 2005 and 2013.

The increasing importance of the static OP covariance for aggregate productivity is suggestive of the fact that reallocation may have played a major role in shaping the dynamics of Italian labour productivity in the period of observation. The decomposition outlined in equation (7) allows us to shift our focus to the growth rate of aggregate productivity - a more relevant variable both for policy and welfare considerations - and to have a more complete picture of the reallocation process, including firm demography as well.

Table 2 shows the results obtained applying the above-mentioned decomposition to our firm-level data. The first column contains the contribution of incumbent firms' average productivity to the dynamics of aggregate productivity; this contribution reflects both variations in technical efficiency at the firm level and fluctuations in the demand faced by firms, that may influence - especially in the short run the pricing strategies of firms. ${ }^{8}$ The second column shows the contribution of the reallocation among the surviving firms; in other words, it tells how much of the observed productivity dynamics depends on reallocation of employment shares to the most efficient firms. The contribution of entry (third column) is typically negative, as it reflects the lower productivity of these firms with respect to the incumbents;

7 For sake of simplicity, we have described here the baseline Melitz and Polanec (2015) decomposition, which defines aggregate productivity as a weighted average of individual firms' log productivities. Despite returning a straightforward decomposition, this approach has two drawbacks: (i) the growth of aggregate productivity measured in logs does not correspond to that of aggregate productivity measured in levels, which is the one that should be preferred when evaluating welfare implications (Petrin and Levinsohn, 2012); (ii) in the baseline decomposition, the covariance term would not be invariant to changes in average productivity (i.e. a uniform increase in productivity for all firms would also map into the covariance term, rather than on the within-firm productivity term only). Melitz and Polanec (2015:374) explain how these issues can be addressed, by performing the decomposition on data in levels and by defining a scale-independent covariance term. All the results presented in this article are obtained using this decomposition in levels.

8 It has to be stressed that we are not able to perfectly control for price variations, since the deflators at our disposal are disaggregated at the 2-digits level. Hence, price variations may still show up in our data, as long as they depart from the average price dynamics within each 2-digit sector. 
Table 2: The Decomposition of Aggregate Productivity's Dynamics

\begin{tabular}{|c|c|c|c|c|c|c|}
\hline & \multicolumn{2}{|c|}{ Surviving firms } & \multicolumn{3}{|c|}{ Firm demography } & \multirow[b]{2}{*}{$\begin{array}{c}\text { Aggregate } \\
\text { productivity }\end{array}$} \\
\hline & $\begin{array}{c}\text { Average } \\
\text { productivity }\end{array}$ & Reallocation & Entry & Exit & Net & \\
\hline \multicolumn{7}{|c|}{ Manufacturing } \\
\hline 2005--06 & 3.43 & 3.04 & -0.87 & 1.15 & 0.28 & 6.75 \\
\hline 2006--07 & -0.07 & 1.73 & -0.98 & 1.24 & 0.26 & 1.92 \\
\hline 2007--08 & -4.31 & 0.91 & -0.96 & 1.14 & 0.18 & -3.22 \\
\hline 2008--09 & -17.66 & 3.72 & -0.73 & 1.62 & 0.89 & -13.05 \\
\hline 2009--10 & 7.30 & 6.89 & -1.10 & 1.61 & 0.52 & 14.70 \\
\hline 2010--11 & -1.63 & 5.67 & -1.19 & 1.17 & -0.02 & 4.02 \\
\hline 2011--12 & -4.93 & 2.69 & -1.03 & 1.18 & 0.15 & -2.09 \\
\hline 2012--13 & -4.56 & 5.89 & -1.07 & 1.51 & 0.45 & 1.77 \\
\hline 2005--13 & -14.73 & 21.75 & -6.71 & 8.55 & 1.84 & 8.86 \\
\hline \multicolumn{7}{|c|}{ Services } \\
\hline 2005--06 & -2.04 & 3.44 & -2.09 & 2.59 & 0.50 & 1.90 \\
\hline 2006--07 & -0.92 & 1.16 & -2.41 & 2.45 & 0.04 & 0.27 \\
\hline 2007--08 & -2.93 & -0.48 & -2.16 & 2.45 & 0.29 & -3.11 \\
\hline 2008--09 & -9.55 & 0.49 & -1.76 & 2.93 & 1.17 & -7.89 \\
\hline 2009--10 & -0.02 & 5.79 & -2.38 & 2.65 & 0.27 & 6.03 \\
\hline 2010--11 & -5.49 & 3.95 & -2.80 & 3.01 & 0.21 & -1.34 \\
\hline 2011--12 & -5.66 & 0.20 & -2.46 & 2.77 & 0.31 & -5.16 \\
\hline 2012--13 & -4.91 & 4.55 & -2.76 & 3.29 & 0.53 & 0.18 \\
\hline 2005--13 & -11.76 & 4.86 & -10.93 & 8.46 & -2.47 & -9.37 \\
\hline \multicolumn{7}{|c|}{ Total } \\
\hline 2005--06 & -1.20 & 4.50 & -1.79 & 2.13 & 0.34 & 3.64 \\
\hline 2006--07 & -0.79 & 1.52 & -2.06 & 2.10 & 0.05 & 0.77 \\
\hline 2007--08 & -3.14 & -0.39 & -1.87 & 2.06 & 0.20 & -3.33 \\
\hline 2008--09 & -10.66 & -0.57 & -1.49 & 2.58 & 1.09 & -10.14 \\
\hline 2009--10 & 0.99 & 7.80 & -2.14 & 2.37 & 0.23 & 9.02 \\
\hline 2010--11 & -4.95 & 5.57 & -2.48 & 2.52 & 0.04 & 0.67 \\
\hline 2011--12 & -5.54 & 1.32 & -2.18 & 2.35 & 0.17 & -4.05 \\
\hline 2012--13 & -4.85 & 5.10 & -2.39 & 2.85 & 0.46 & 0.71 \\
\hline $2005--13$ & -12.46 & 10.41 & -10.99 & 9.25 & -1.74 & -3.79 \\
\hline
\end{tabular}

Notes: Net demography is defined as the sum of entry and exit.

The decomposition on the 2005-13 period is not obtained by cumulating the contributions across years, but is instead obtained by applying the Melitz-Polanec decomposition on the initial and final year only. This means that the groups of incumbents, entrants and exiters are not directly comparable to the ones taken into account in the year-by-year exercises. This may lead to some counter-intuitive results: as an example, the annual net contribution from firm demography is positive in all years, but the contribution over the entire period is negative.

such a productivity divide may derive on one side from the smaller size of entrants, on the other from the fact that newborn firms tend to compress their markups, setting up more aggressive price strategies upon entry, in order to rapidly acquire market shares (Foster et al., 2016) thus reducing measured labour productivity. The positive contribution of exit, instead, reflects the selection mechanisms that force the exit from the market of the least productive firms.

In the period under analysis (2005-13), aggregate productivity in manufacturing has risen by 8.9 per cent, despite the fall experienced in correspondence to the two episodes of economic crisis. The generalized decline of average productivity has been counterbalanced by a positive contribution of reallocation in every year of our sample. Despite being positive in the vast majority of the cases, in services the reallocation has not been strong enough to counterbalance the steady decline experienced in terms of average productivity; this had a detrimental impact on the overall dynamics of aggregate productivity, which fell by 9.4 per cent over the 2005-13 period. Both in manu- 


\section{Table 3: Firm Demography}

\begin{tabular}{|c|c|c|c|c|c|c|c|c|}
\hline & 2006 & 2007 & 2008 & 2009 & 2010 & 2011 & 2012 & 2013 \\
\hline & \multicolumn{8}{|c|}{ Manufacturing } \\
\hline Entry rate & 5.55 & 5.35 & 5.36 & 4.39 & 4.42 & 4.83 & 4.47 & 4.58 \\
\hline Entrant share of VA & 1.78 & 1.75 & 2.07 & 1.62 & 1.62 & 1.93 & 1.88 & 1.91 \\
\hline Entrant relative size $(1,2)$ & 30.50 & 34.07 & 36.61 & 35.97 & 37.31 & 37.33 & 40.24 & 41.02 \\
\hline Entrant relative productivity $(2)$ & 82.77 & 80.31 & 84.40 & 81.75 & 82.65 & 80.90 & 73.13 & 74.71 \\
\hline Exit rate & 5.60 & 5.72 & 5.98 & 7.13 & 5.84 & 5.65 & 6.68 & 6.84 \\
\hline Exiting share of VA & 1.23 & 1.08 & 1.23 & 1.61 & 1.16 & 0.93 & 1.09 & 1.34 \\
\hline Exiting relative size $(1,3)$ & 19.43 & 16.63 & 19.11 & 20.19 & 18.63 & 15.04 & 13.76 & 16.65 \\
\hline \multirow[t]{2}{*}{ Exiting relative productivity (3) } & 81.79 & 64.01 & 63.65 & 64.14 & 60.14 & 57.31 & 53.95 & 50.22 \\
\hline & \multicolumn{8}{|c|}{ Services } \\
\hline Entry rate & 9.67 & 11.02 & 9.29 & 7.96 & 8.02 & 8.92 & 7.82 & 7.95 \\
\hline Entrant share of VA & 3.81 & 4.41 & 4.17 & 3.56 & 3.80 & 4.13 & 3.57 & 3.55 \\
\hline Entrant relative size $(1,2)$ & 40.87 & 40.19 & 45.19 & 45.59 & 48.34 & 41.74 & 46.71 & 42.90 \\
\hline Entrant relative productivity (2) & 74.86 & 75.05 & 78.14 & 75.62 & 74.45 & 70.92 & 62.88 & 69.72 \\
\hline Exit rate & 6.31 & 6.27 & 7.69 & 8.09 & 7.26 & 8.47 & 9.09 & 10.15 \\
\hline Exiting share of VA & 2.28 & 1.98 & 2.39 & 2.83 & 2.27 & 2.40 & 2.52 & 2.80 \\
\hline Exiting relative size $(1,3)$ & 33.92 & 30.74 & 43.61 & 32.78 & 32.61 & 29.20 & 24.82 & 23.44 \\
\hline \multirow[t]{2}{*}{ Exiting relative productivity (3) } & 71.79 & 67.56 & 72.03 & 62.17 & 74.76 & 52.51 & 53.60 & 46.15 \\
\hline & \multicolumn{8}{|c|}{ Total } \\
\hline Entry rate & 7.70 & 8.31 & 7.41 & 6.25 & 6.30 & 6.96 & 6.22 & 6.34 \\
\hline Entrant share of VA & 2.84 & 3.14 & 3.17 & 2.63 & 2.75 & 3.08 & 2.76 & 2.77 \\
\hline Entrant relative size $(1,2)$ & 35.98 & 37.35 & 41.20 & 41.09 & 43.17 & 39.71 & 43.70 & 42.03 \\
\hline Entrant relative productivity (2) & 78.52 & 77.44 & 80.95 & 78.44 & 78.16 & 75.49 & 67.63 & 72.04 \\
\hline Exit rate & 5.97 & 6.01 & 6.87 & 7.63 & 6.58 & 7.12 & 7.94 & 8.57 \\
\hline Exiting share of VA & 1.78 & 1.55 & 1.83 & 2.24 & 1.74 & 1.69 & 1.84 & 2.10 \\
\hline Exiting relative size $(1,3)$ & 26.69 & 23.66 & 32.04 & 26.81 & 25.97 & 22.54 & 19.60 & 20.25 \\
\hline Exiting relative productivity (3) & 76.59 & 65.85 & 68.19 & 63.07 & 68.11 & 54.67 & 53.76 & 48.05 \\
\hline
\end{tabular}

Notes: Average values across the 315 5-digit industries belonging to manufacturing.

(1)In terms of value added.

(2) With respect to surviving firms

(3) With respect to active firms at $t$.

facturing and services, our results show two clear and to some extent diverging patterns. On the one hand, the reallocation of resources from least to most productive firms contributed positively to aggregate productivity growth; on the other hand, the fall in average productivity hampered productivity growth. As discussed in the introduction, the decline in average productivity measured as real value added per worker might be interpreted with caution because it might not reflect changes in technical efficiency; nonetheless, its decline is neither surprising nor new for the case of Italy. Several studies have documented the structural weak- nesses of the Italian economy (e.g. size distribution of firms, high share of family-owned firms and low propensity to innovate, among others) that are limiting productivity growth (Brandolini and Bugamelli (2009)).

Aggregate productivity has also been influenced by firm demography. As expected, the entry component is always negative (since entrants are, on average, less productive than incumbents), and the exit one is always positive (since exiting firms are less productive than incumbents, as well). Overall, the net contribution of firm entry and exit has sustained the dynamics of aggregate productivity in almost 
all years, despite being relatively small in magnitude; the contribution of firm demography has been substantially higher in the years of deepest financial crisis (2008-09), as a result of an increase in the exit component induced by a more pronounced selectivity on the market.

Ultimately, the contribution of firm demography depends on two factors: on one side, the rates of entry/exit from the market; on the other, the relative productivity of entering and exiting firms with respect to the incumbents. The dynamics of these two factors is reported in Table 3. Services are characterized by substantially higher entry and exit rates relative to manufacturing. Moreover, while in manufacturing the exit rate is always higher than the entry rate, ${ }^{9}$ in services it is usually the opposite, ${ }^{10}$ if we exclude the sudden tightening up of the selection process in the most acute phase of the sovereign debt crisis (2012 and 2013).

Entry rates in both manufacturing and services have shrunk over time, while the pattern followed by exit rates is less clear-cut; it is apparent, though, that exit rates suddenly increased in the years of crisis, suggesting that recessions influence firm demography mainly by pushing firms out of the market, rather than by preventing the entrance of new firms. Looking at relative size and productivity of these firms with respect to incumbents, new entrants in manufacturing tend to be smaller but more productive with respect to those in services. Relative productivity has been declining for both entering and exiting firms throughout the whole period of observation, more intensely in manufacturing, where - as shown in Table 2 - the process of reallocation has sustained the aggregate productivity of incumbents.

\section{Netting from Sectoral Composition}

The results of the aggregate labour productivity decomposition presented in Table 2 may crucially depend on composition effects: the relative weight of the four components could be different across more narrowly-defined sectors, as it is likely to be influenced by structural sectoral characteristics - such as the degree of competitiveness or the exposure to international trade, for example. In order to check whether our results are significantly affected by these composition effects, we have replicated the dynamic OP decomposition on each narrowly-defined sector (according to the 5-digit Ateco 2007 classification), pooled together all the sectors, and estimated for each component the following OLS model:

$$
\Delta y_{s t}=\delta_{s}+\delta_{t}+\varepsilon_{s t}
$$

where $\Delta y$ is one of the four components of aggregate labour productivity growth between year $\mathrm{t}$ and $\mathrm{t}-1$ (as defined in equation (7)), $\mathrm{s}$ indexes 5 -digit sectors, $\mathrm{t}$ indexes years, $\delta_{\mathrm{s}}$ are sector fixed effects, $\delta_{t}$ are fixed effects for year $t$, and $\varepsilon_{\mathrm{st}}$ is an error term. The idea behind this specification is to control for invariant sectoral characteristics by means of the sectoral fixed effects $\delta_{s}$. The year fixed effects $\delta_{\mathrm{t}}$ estimated under this framework can thus be interpreted as the contribution of each component to the dynamics of aggregate productivity, net of the composition effects discussed above. ${ }^{11}$

For each component, Chart 2 plots the estimated year fixed effects for the total economy. The results presented in Table 2 are broadly confirmed; moreover, the evolution over time of the various components emerges now more clearly, highlighting in particular the steadilyincreasingly positive role of reallocation in

9 This is coherent with other data sources - such as the Infocamere database - that provide information on firm demography in manufacturing.

10 This pattern has been also documented in Lotti (2007). 
Chart 2: The Decomposition of Productivity Dynamics, Net of Sectoral Fixed Effects, 2006-2013

Aggregate Productivity (Weighted)

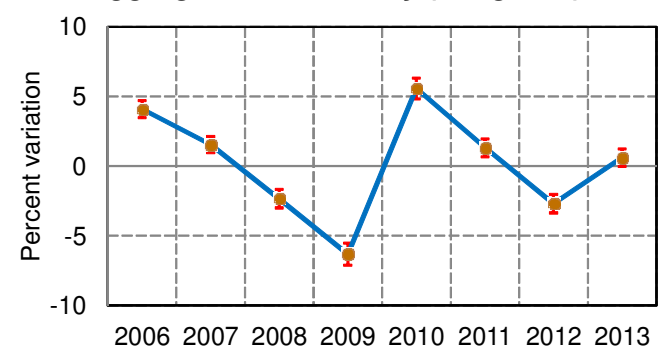

Average Productivity (Unweighted)

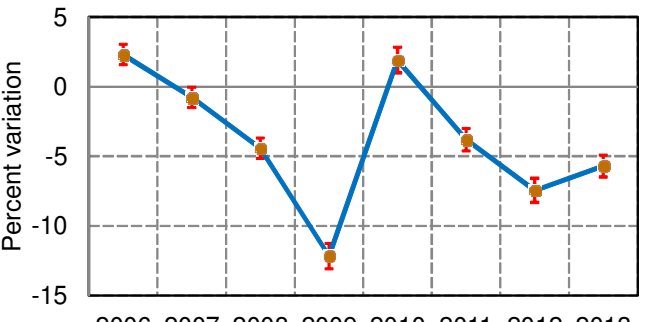

20062007200820092010201120122013

Entrant

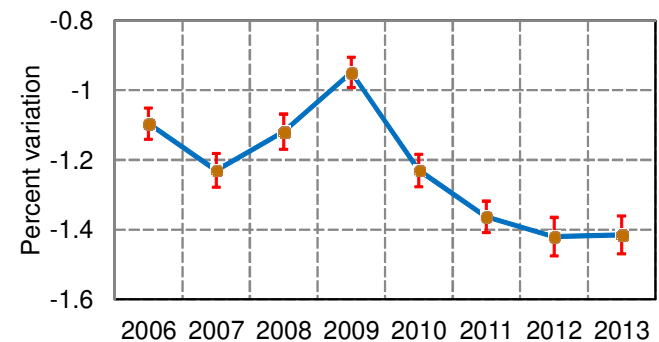

Incumbents
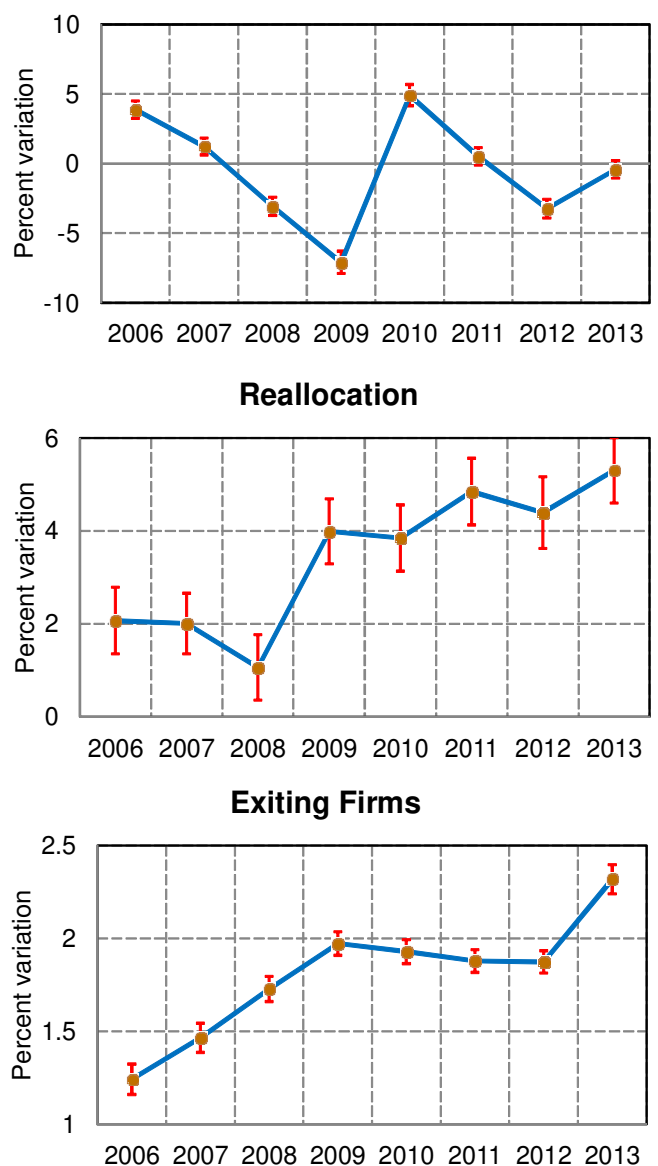

Notes: Dependent variables were winsorized at the 5th and 95th percentile across the whole sample.

Aggregate productivity growth expressed in per cent, is the sum of productivity growth in incumbents, entrants and exiting firms. Productivity growth in incumbents is the sum of unweighted average productivity growth and reallocation, expressed in percentage points.

counterbalancing the fluctuations in averagefirm productivity.

Net of sectoral composition, aggregate labour productivity - which was moderately increasing until 2007 - experienced a conspicuous swing in the years of the financial crisis and then settled on a pattern of sluggish growth, interrupted by a new trough at the onset of the sovereign debt crisis. This pattern is largely dominated by the contribution of incumbent firms, which summarizes the often diverging contribution of the average productivity and of the reallocation terms: on one side, the firms' average productivity sluggishly growing at the beginning of our sample - suffered sharp declines in correspondence to the

11 When applied to narrowly-defined sectors, the dynamic OP decomposition may return extremely high values (in absolute terms) on some of its components; this is typically the case when dealing with sectors characterized by a few small firms. When we estimate model 8, it is therefore particularly important to clean for these outliers, that may severely affect our estimates, despite having little relevance in aggregate terms. To do that, we winsorize our dependent variables - i.e. the contribution to aggregate productivity growth of each component in equation 7 - at the $5^{\text {th }}$ and $95^{\text {th }}$ percentile across the whole sample. 


\section{Table 4: Elasticity of the Aggregate Productivity Components to the Sectoral Business Cycle}

\begin{tabular}{llllll} 
& Average productivity & Reallocation & Entry & Exit & Aggregate productivity \\
\hline Manufacturing & $0.1345^{* * *}$ & $0.0644^{* *}$ & $-0.0039^{* * *}$ & -0.0006 & $0.1683^{* * *}$ \\
& {$[0.036]$} & {$[0.026]$} & {$[0.001]$} & {$[0.001]$} & {$[0.050]$} \\
Services & $0.0742^{* * *}$ & $0.0423^{* * *}$ & -0.0018 & $-0.0033^{* * *}$ & $0.0956^{* * *}$ \\
& {$[0.026]$} & {$[0.015]$} & {$[0.002]$} & {$[0.001]$} & {$[0.025]$} \\
Total economy & $0.1087^{* * *}$ & $0.0522^{* * *}$ & $-0.0024^{* *}$ & $-0.0027^{* * *}$ & $0.1295^{* * *}$ \\
& {$[0.022]$} & {$[0.014]$} & {$[0.001]$} & {$[0.001]$} & {$[0.026]$} \\
\hline
\end{tabular}

Note: The reported coefficients are the elasticities of each component to the sectoral business cycle, are captured by an aggregate sales index computed for each sector at the 5 digit level of disaggregation. Standard errors clustered at the sectoral level ( 5 digit). All the regressions have been weighted by the number of employees in each sector.

two crisis episodes, and negatively weighed on aggregate productivity in all post-crisis years, except 2010; on the other side, the contribution of reallocation - initially less sizable - experienced a considerable jump at the onset of the financial crisis, maintaining its contribution at the same high levels in the following years. Adding to the positive effect of the reallocation process, the contribution of firm demography strengthened over the period of observation, thanks to the relevant increase of the exit component, driven by a more selective market environment after the two crisis episodes. These broad tendencies are largely confirmed when the exercise is repeated for manufacturing and services separately. ${ }^{12}$ The most notable difference relates to the contribution of reallocation, which - despite being similar in size at the beginning of the sample - experienced a stronger increase for the firms in services than for those in manufacturing; nonetheless, the former were penalized by worse dynamics of the average productivity term.

\section{Cyclical Fluctuations}

The results presented in the previous sections do not disentangle the effect that different cyclical conditions at the sectoral level may have on the four components in the aggregate productivity decomposition. In order to explore the role of the business cycle, we enrich equation 8 with an additional term, exploiting the information on real sales at the industry level. More specifically, we estimate the following regression by OLS:

$$
\Delta y_{s t}=\delta_{s}+\delta_{t}+\beta \Delta \mathrm{I}_{s t}+\varepsilon_{s t}
$$

where $\Delta \mathrm{I}_{\mathrm{st}}$ is the growth rate of a real sales index for each 5-digit sector $\mathrm{s}$ between years $\mathrm{t}-1$ and $t$. In this case, our coefficient of interest is $\beta$, representing the elasticity of each component of labour productivity to the business cycle at the industry level.

Table 4 collects the estimated $\beta$ coefficients for each component, and for manufacturing and services separately. The first two columns confirm that both average productivity and reallocation among existing firms are procyclical: a one-standard-deviation increase in the growth of real sales is associated with an increase of average productivity and reallocation by 1.1 and 0.5 percentage points, respectively. The elasticity on average productivity is stronger in manufacturing, while the one on the reallocation component is not statistically different between the two sectors. As regards the exten-

12 These results are shown in Charts C.1 and C.2 in the appendix at: http://www.csls.ca/ipm/32/

Linarello_Petrella\%20Appendix.pdf 


\section{Table 5: The Aggregate Productivity Components in the Long Run vs. Sectoral Characteristics}

\begin{tabular}{lccccc}
\hline & Average productivity & Reallocation & Entry & Exit & Aggregate productivity \\
\hline \multirow{2}{*}{ log Herfindahl } & & & Panel (a): & & \\
& -0.8766 & $1.6105^{* *}$ & $0.3955^{*}$ & $-0.6597^{* * *}$ & $1.4351^{* *}$ \\
N & {$[0.884]$} & {$[0.732]$} & {$[0.214]$} & {$[0.197]$} & {$[0.706]$} \\
R2 & 580 & 580 & 577 & 576 & 580 \\
& 0.007 & 0.032 & 0.016 & 0.052 & 0.026 \\
ImpPen developing & -8.9043 & $25.7745^{*}$ & -5.1873 & $22.7467^{* * *}$ & 18.7375 \\
& {$[15.348]$} & {$[13.732]$} & {$[5.632]$} & {$[4.613]$} & {$[16.677]$} \\
N & 184 & 189 & 191 & 190 & 190 \\
R2 & 0.003 & 0.037 & 0.020 & 0.224 & 0.016 \\
\hline
\end{tabular}

Note: Robust standard errors. All the regressions have been weighted by the number of employees in each sector. The regressions in panel (a) have been performed on data disaggregated at the 5-digit level. Those in panel (b), instead, refer to manufacturing sector only, and have been performed at the 4-digit level, since data on import penetration were not available at a more disaggregated level.

sive margins (i.e. entry and exit), columns 3 and 4 show that both elasticities are negative and smaller in size with respect to the intensive margins. A negative elasticity of entry means that - during booms - the negative contribution of entry to aggregate productivity growth is stronger. It is interesting to notice that the aggregate effect is driven by the estimates in the manufacturing industries, for which the coefficient is statistically significant. This elasticity is in line with the evidence relative to the years of the global financial crisis (2008 and 2009), but are at odds with the results for the aggregate productivity decomposition during the sovereign debt crisis (2012-13). However, while the first crisis triggered a credit crunch that reduced the availability of finance to less productive new initiatives; the second crisis was characterized by a fall in aggregate demand and an increase in uncertainty that reduced the average productivity of new projects. A negative elasticity of exit has a different interpretation because it implies that during recessions the positive contribution of exit to aggregate productivity growth is stronger. The correlation is coherent with a large body of literature, that claims that during recessions selection processes are tougher. ${ }^{13}$

\section{Industry Characteristics}

Finally, we explore to what extent the four components of equation (7) are influenced by structural characteristics at the industry level. In order to do so, we perform an OLS estimation on the following regression:

$\Delta y_{s}^{L R}=\beta x_{s, t O}+\varepsilon_{s}$

where $\Delta \mathrm{y}_{s}{ }^{\mathrm{LR}}$ is the long-run sectoral contribution (between 2005 and 2013) of each of the four components defined in equation (7), $\mathrm{x}_{\mathrm{s}, \mathrm{t}}$ is the structural sectoral characteristic of interest in sector s, measured at the begining of the period, and $\varepsilon_{\mathrm{s}}$ is an error term.

Market structure In the panel (a) of table 5 , we look at the effect of the degree of concentration within each industry, measured by means of the Herfindahl index on sales (mea-

13 In this sense, our results are coherent with the theoretical and empirical literature that investigated the cleansing effect of recessions (Caballero and Hammour, 1994; Foster et al., 2014). 


\section{Chart 3: Entry and Exit Probability, by Percentile of the Productivity Distribution}

\section{a) Entry}

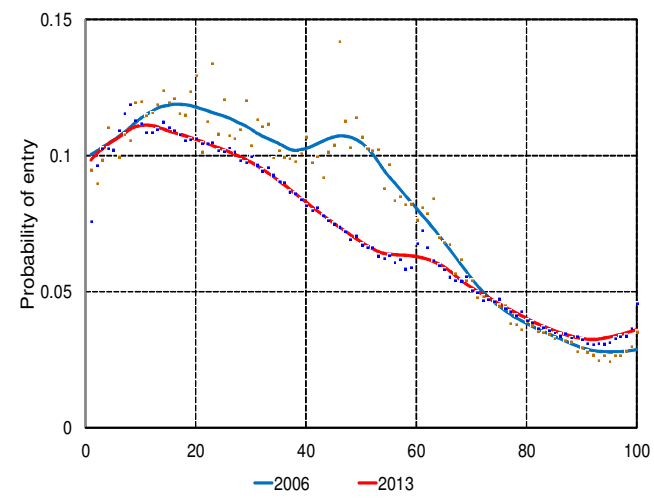

sured in logs): $x_{s, t 0}=\ln \left(H_{s, 2005}\right)$. The last column indicates that more concentrated industries experience higher aggregate productivity growth. By looking at the different components, it is apparent that the overall effect is likely to be driven by reallocation. In concentrated industries the positive effect of reallocation is stronger: a 1 per cent increase in the concentration index leads to a 0.2 per cent increase of the reallocation component. This might reflect the "winner takes all" dynamics, i.e. the fact that technological leaders increase their advantage with respect to laggard firms. Significant effects also emerge in terms of firm demographics: our results show that in more concentrated sectors the negative contribution of entry and the positive contribution of exit are attenuated in size. In the case of exit, this result is mostly driven by the fact that exit rates tend to be lower in more concentrated sectors. As regards entry, instead, the attenuation is mainly due to the fact that in concentrated sectors the entrants are more similar to incumbents in terms of relative productivity, probably as a consequence of higher barriers to entry.

Import penetration In the last two decades, Italy has been exposed to a substantial increase in competition from abroad (especially from developing countries), as a consequence of the b) Exit

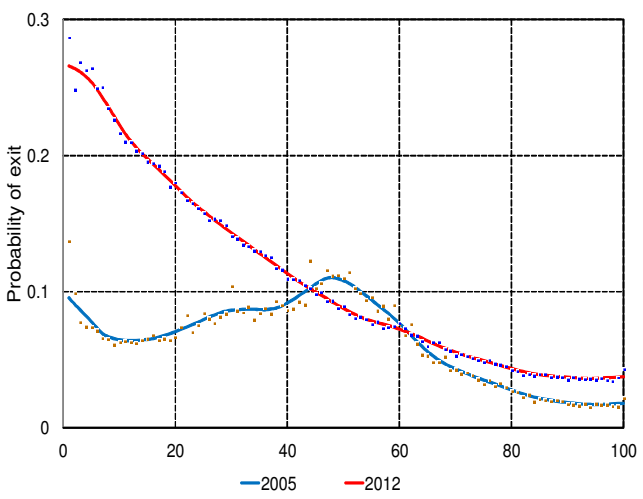

gradual reduction in trade costs and of the process of globalization; this induced a deep restructuring of the Italian productive system, that is likely to have influenced the dynamics of aggregate productivity. We therefore focus on the manufacturing sector and look at the correlation between import penetration from developing countries and the different components of the aggregate productivity decomposition. Import penetration is measured as the share of imports from developing countries in domestic consumption; it has been computed for each 4digit industry, and refers to year 2005. The results are displayed in panel (b) of Table 5. Despite being non-significant for aggregate productivity as a whole, import penetration from developing countries has an impact on some of its components. In particular, import penetration has a strong and positive effect on reallocation and exit; this might be consistent with the fact that a greater exposure to competition from developing countries favors the exit of least productive firms and the reallocation of resources towards most productive incumbents. The effect is sizable: a one-standarddeviation increase in the import penetration index is associated with an increase of the reallocation and exit components by 3 and 2.6 per cent, respectively. 


\section{Chart 4: Employment Growth, by Percentile of the Productivity Distribution}

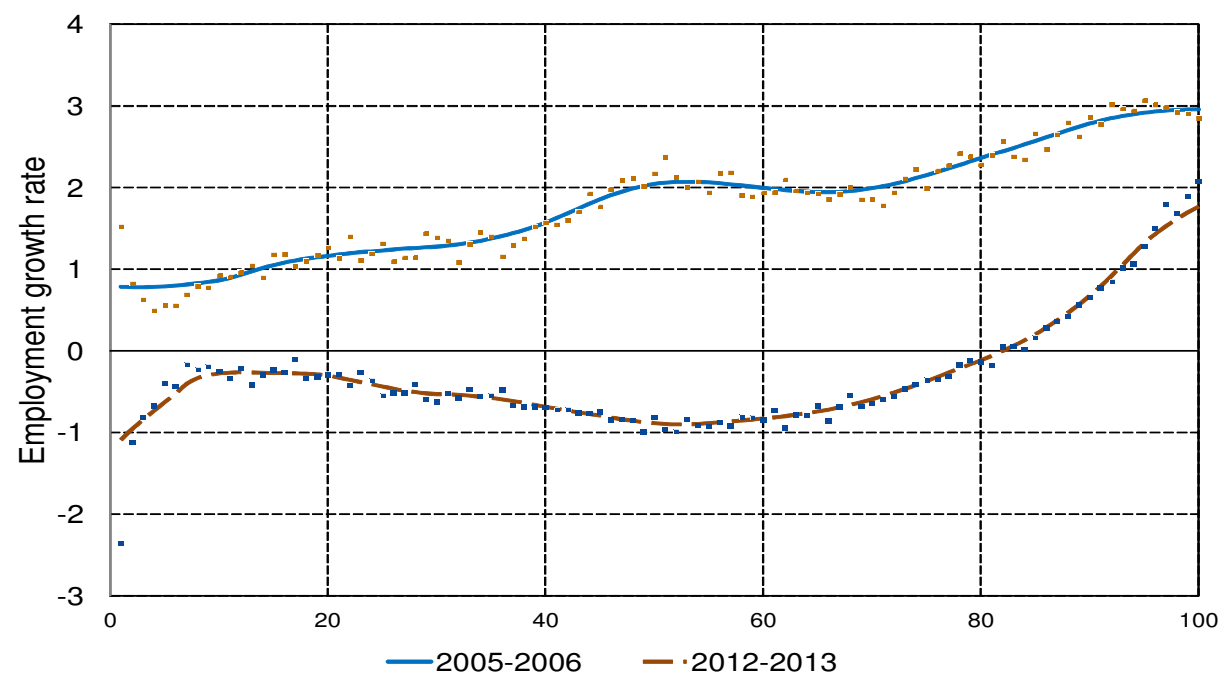

\section{Chart 5: The Evolution of OP Covariance Across Samples}

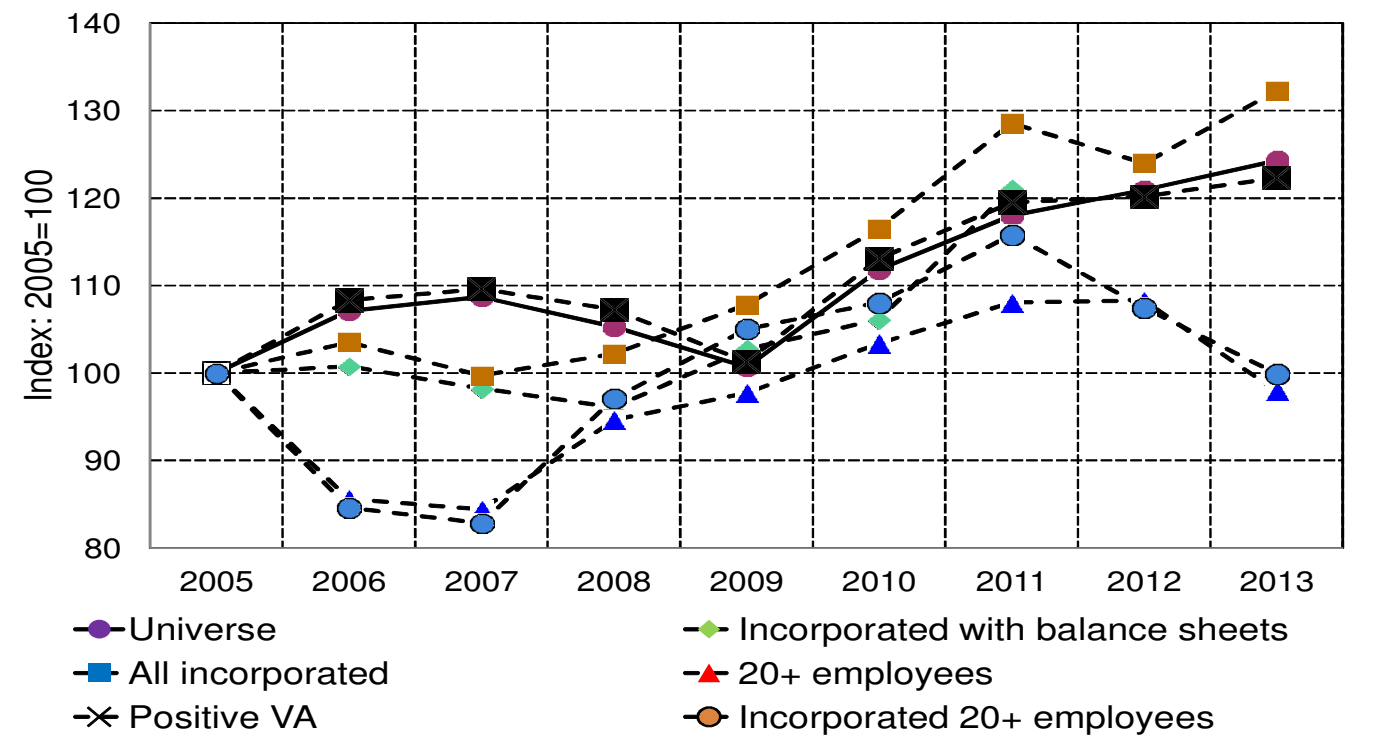

\section{Effects Along the Productivity Distribution}

In this section we provide some suggestive evidence at the firm and industry level on the underlying mechanisms of the documented increase in allocative efficiency in Italy between 2005 and 2013.

We start by exploiting our firm level data. First, we divide firms into within-industry percentiles of the labour productivity distribution; second, for each percentile we compute the entry rate, the exit rate and the average employment growth of surviving firms. The left panel of Chart 3 shows the entry rates in 2006 and in 2013. As already documented in Table 3, entry rates have fallen in Italy. As the chart shows, however, the decline has not been homogeneous along the productivity distribution. Entry rates fall up to the $70^{\text {th }}$ percentile of the productivity distribution, while they remain almost unchanged for top percentiles. The right panel shows the exit rates in 2005 
and 2012. Exit rates increased for almost all percentiles of the productivity distribution; nonetheless, they more than doubled for the lowest percentiles, while the increase has been very small among the most productive firms.

Chart 4 reports the average employment growth of surviving firms in 2005-06 and in 2012-13. In 2005-06 employment growth was higher for the more productive firms, ranging from almost 1 per cent among firms in the lowest percentiles to about 3 per cent for firms in the top percentiles of the productivity distribution. This corroborates the evidence presented in the previous sections, showing that the contribution of reallocation to aggregate productivity growth in Italy was positive even before the crisis. In 2012-13 employment growth declined for all firms; it became negative for firms up the the $80^{\text {th }}$ percentile of the productivity distribution, and it remained positive for the most productive firms. Overall, this pattern positively contributed to the strengthening of the allocative efficiency of the Italian economy.

\section{The Importance of Observing the Universe of Firms: A Comparison With Other Popularly Used Data}

Among the features of this work, the completeness and the quality of the data used are two of the most relevant aspects; this is especially true for the Italian case, since this article is the first one - to our knowledge - that exploits data on the universe of Italian firms to analyze productivity dynamics. In order to stress the importance of having access to data on the universe of firms, we have fictitiously reduced our sample, and then compared our results with those obtained from different sample cuts that are commonly used in the literature.

Chart 5 summarizes the discrepancies across different sample cuts, by showing the evolution of the covariance term deriving from the static OP decomposition across different sample cuts. To produce the graph, we perform the static OP decomposition on progressively smaller samples to obtain the weight of the OP covariance term on the aggregate productivity of each subsample. The series of these weights are then converted to index numbers to better analyze their evolution.

The results highlight stark differences across sample cuts. As a matter of fact, most of the sample cuts fail to single out the increased weight of the OP covariance term in the years 2005-07 and its reduction at the onset of the global financial crisis (2008-09), which are only captured by the full sample (either including or excluding firms with negative value added). The subsequent recovery is captured by the samples that only include incorporated firms, but not by the samples with 20 or more employees, which display divergent dynamics.

\section{Conclusion}

In this article we exploit a unique dataset covering the universe of Italian firms operating in the non-agricultural and non-financial sector over the period 2005-2013, in order to document the contribution of allocative efficiency to the dynamics of aggregate labour productivity. Following the Olley and Pakes methodology, we have decomposed aggregate labour productivity as the sum of firm average productivity and a term capturing the strength of allocative efficiency. We find that allocative efficiency increased by almost 7 percentage points between 2005 and 2013.

We then analyzed the the dynamics of aggregate labour productivity, distinguishing between the contribution of different factors: on one side, the contribution of incumbent firms, depending on both the average firm productivity and the reallocation of resources across firms; on the other, the contribution of firm demographics (entry and exit of firms in 
the market), mainly driven by selection mechanisms. The reallocation component - net of sectoral composition effects - positively contributed to the dynamics of aggregate productivity in all years, even before the burst of the global financial crisis (years 2005-07 in our sample). Over the whole period 2005-13, it steadily increased its relevance. The net contribution of firm demography is always positive in our sample: the positive contribution linked to the exit of least productive firms more than compensated the negative contribution arising from the entry of small low-productivity newborn firms.

The contribution of the different components to the dynamics of aggregate productivity varies according to the business cycle. Average productivity and reallocation are both procyclical, consistent with the evidence that firms tend to invest more when they experience a positive demand shock. The contribution of entry and exit is, instead, countercyclical, pointing at a more stringent selection process during recessions. Reallocation is also stronger in sectors that were more exposed to competition from developing countries; this might have favored an improvement of allocative efficiency through the exit of the least productive firms and the subsequent reallocation of resources towards the most productive incumbents.

Over the period of observation, the different response of entry rates, exit rates and employment growth along the productivity distribution also provides some suggestive evidence on the mechanisms behind the observed increase in allocative efficiency. In the same time span, exit rates increased and entry rates dropped for firms in the low tail of the productivity distribution, suggesting that the prolonged phase of recession gave rise to a more selective environment. Moreover, average firm employment growth declined across the whole distribution, becoming negative for the firms in the lower tail. Overall, these results suggest that the structural adjustment of the Italian productive system - already in action before the global financial crisis - reinforced during the prolonged period of recession; such adjustment predominantly occurred through the exit of the least productive firms and the reallocation of workforce to the best performing ones.

To our knowledge, this article is the first one that analyzes productivity dynamics using detailed data on the universe of Italian firms. The advantage of using complete and high-quality data is non-negligible: we show that different sample cuts, often used in the literature, fail to capture the changes in the incidence of allocative efficiency over aggregate productivity.

\section{References}

Abbate, C. C., M. G. Ladu, and A. Linarello (2017) "An Integrated Dataset of Italian Firms: 20052013”, Bank of Italy Occasional Paper, forthcoming.

Aghion, P., R. Blundell, R. Griffith, P. Howitt, and S. Prantl (2009) "The Effects of Entry on Incumbent Innovation and Productivity," Review of Economics and Statistics, Vol. 91, No. 1, pp. 20-32.

Andrews, D. and F. Cingano (2014) "Public Policy and Resource Allocation: Evidence from Firms in OECD Countries," Economic Policy, Vol. 29, No. 78, pp. 253-296.

Bartelsman, E., S. Scarpetta, and F. Schivardi (2005) "Comparative Analysis of Firm Demo- Graphics and Survival: Evidence from Micro-Level Sources in OECD Countries," Industrial and Corporate Change, Vol. 14, No.3, pp. 365-391.

Bartelsman, E., J. Haltiwanger, and S. Scarpetta (2009) "Measuring and Analyzing Cross- Country Differences in Firm Dynamics," Producer Dynamics: New Evidence from Micro Data. (Chicago: University of Chicago Press), pp. 15-76.

Bartelsman, E., J. Haltiwanger, and S. Scarpetta (2013) "Cross-country Differences in Productivity: The Role of Allocation and Selection," American Economic Review, Vol. 103, No.1, pp. 305-334.

Bernard, A. B., J. B. Jensen, and P. K. Schott (2006) "Survival of the Best Fit: Exposure to Low-Wage Countries and the (uneven) Growth of US Manufacturing Plants," Fournal of International Economics, Vol. 68, No.1, pp. 219-237.

Bloom, N. and J. Van Reenen (2010) "Why do Management Practices Differ Across Firms and 
Countries?" Fournal of Economic Perspectives, Vol. 24, No. 1, pp. 203-224.

Brandolini, A. and M. Bugamelli (2009) "Report on Trends in the Italian Productive

System," Bank of Italy Occasional Paper Vol. 45, pp. $1-169$.

Caballero, R. J. and M. L. Hammour (1994) "The Cleansing Effect of Recessions," American Economic Review, Vol. 84, No. 5, pp. 1350-1368.

Calligaris, S., M. Del Gatto, F. Hassan, G. I. P. Ottaviano, and F. Schivardi (2016) "Italy's Productivity Conundrum: A Study on Resource Misallocation," European Economy Discussion Paper 030, European Commission.

Cette, G., J. Fernald, and B. Mojon (2016). "The Pre-Great Recession Slowdown in Pro- ductivity," European Economic Review.

Foster, L., C. Grim, and J. Haltiwanger (2014) "Reallocation in the Great Recession: Cleaning or Not?" Working Paper No. 20427. National Bureau of Economic Research.

Foster, L., J. Haltiwanger, and C. Syverson (2016) "The Slow Growth of New Plants: Learning About Demand?" Economica, Vol. 83, No. 329, pp. 91-129.

Gamberoni, E., C. Giordano, and P. Lopez-Garcia (2016) "Capital and Labour (Mis)allocation in the Euro Area: Some Stylized Facts and Determinants," Bank of Italy Occasional Paper Vol. 349 , pp. 1-57.

García-Santana, M., E. Moral-Benito, J. Pijoan-Mas, and R. Ramos (2016) "Growing like Spain: 19952007", Banco de España Working Paper No. 1609.
Geurts, K. and J. Van Biesebroeck (2014) "Job Creation, Firm Creation, and De Novo Entry," CEPR Discussion Paper No. DP10118.

Gopinath, G., S. Kalemli-Ozcan, L. Karabarbounis, and C. Villegas-Sanchez (2015) "Capi- tal Allocation and Productivity in South Europe," Working Paper 21453, National Bureau of Economic Research.

Hsieh, C.-T. and P. J. Klenow (2009) "Misallocation and Manufacturing TFP in China and India," Quarterly Fournal of Economics, Vol. 124, No. 4, pp. 1403-1448.

Lotti, F. (2007) "Firm Dynamics in Manufacturing and Services: A Broken Mirror?" Industrial and Corporate Change, Vol. 16, No. 3, pp. 347-369.

Melitz, M. J. and S. Polanec (2015) "Dynamic Olley-Pakes Productivity Decomposition with Entry and Exit," RAND Fournal of Economics, Vol. 46, No. 2, pp. 362-375.

Olley, G. S. and A. Pakes (1996) "The Dynamics of Productivity in the Telecommunications Equipment Industry," Econometrica, Vol. 64, No. 6, pp. 1263-1297.

Petrin, A. and J. Levinsohn (2012) "Measuring Aggregate Productivity Growth Using PlantLevel Data," RAND Fournal of Economics, Vol. 43, No. 4, pp. 705-725.

Solow, R. M. (1957) "Technical Change and the Aggregate Production Function," Review of Economics and Statistics, Vol. 39, No. 3, pp. 312-320.

Syverson, C. (2011) "What Determines Productivity?" Journal of Economic Literature, Vol. 49, No. 2, pp. 326-365. 


\section{Appendix: ${ }^{14}$}

\section{Dealing with Missing Values}

The validity of our empirical exercise crucially rests on the quality of the data used. One of the main concerns is therefore related to the non-negligible share of firms - especially in the years between 2005 and 2010 - for which we are not able to measure value added. As documented in Abbate et al. (2017), the missing information has been filled by imputing the median value added per worker within cells defined by industry classification, size class, location and legal form.

We present an additional exercise that aims at checking the robustness of our estimates against the exclusion of the imputed information on value added. It would be desirable for us that the results of this exercise closely followed those presented in Table 2; that would allow us to claim that the imputation performed did not significantly distort our estimates. Appendix Table 2 displays the results obtained excluding from the analysis the records with imputed value added: they are completely in line with those presented above both in terms of average productivity and reallocation; some slight difference emerges in the net contribution of firm demography, which is sometimes negative, especially in services. The results obtained for period 2012-13 exactly replicate those presented in Table 2, since in those years data did not present missing values.

Overall, this robustness exercise suggests that the imputation method used to fill in the missing information did not significantly distort the results of our decomposition.

\section{Alternative Productivity Measure}

We have performed the decomposition exercise using as an alternative measure of productivity, namely sales per worker. Since the information on sales is always present in our database, we would be comforted if the relative importance of the four components was similar to the one resulting from the previous exercise on value added per worker. Of course, the two measures differ in many respects. Though different, however, value added per worker and sales per worker broadly share similar dynamics, as shown in Appendix Chart 3: in manufacturing, the dynamics of sales per worker tracks quite closely the one of value added per worker; in services, the two dynamics are still similar, despite showing bigger discrepancies, especially in the last part of the sample. Moreover, it is interesting to look at sales per worker, since it can represent a valid alternative for measuring labour productivity (as in Bartelsman et al. (2013)).

Appendix Table 3 shows the decomposition applied to sales per worker. The results confirm that the reallocation has sustained aggregate dynamics in both manufacturing and services, though experiencing larger swings than in the previous exercise and turning negative in a few cases; the contribution of average sales per worker is largely negative throughout all the sample, just like the average productivity component in Table 2. Entry and exit still offer a negative and positive contribution, respectively, but their net effect — even if small- is not positive in all periods; it is confirmed, however, that the largest contributions from firm demography were registered in the years of the financial crisis (2008-09). 